\title{
Marriage, Family and Kinship in Fiji among Overseas Indians
}

\author{
Kiran Jha* \\ Assistant Professor CSJM University, Kanpur India
}

*Corresponding Author: Kiran Jha, Assistant Professor CSJM University, Kanpur India

\begin{abstract}
Indian immigration and settlement in Fiji was the result of British colonialism whereby Indian labourers were procured under the system of indenture for working on plantations in the latter half of the nineteenth century. Consequently, many Indians stayed on in Fiji making it their permanent habitat. This paper examines cultural and structural aspects of the life of these overseas Indians and contributes to the study of Indian diaspora. It seeks to examine and portray significant attributes of marriage, family and kinship among the settlers. The observance of marriage rituals has a considerable structural significance as social ties are created and reaffirmed. The structure of the family has a bearing on the questions of inheritance, conflict and cooperation, the position of the elders and women in varying situations. The traditional characteristics of the Indian family was sustained among kins through interpersonal relations and household relations. In presenting these facets from a sociological perspective, this paper demonstrates how the Indian cultural identity has been retained by the overseas Indians in Fiji.
\end{abstract}

Keywords: Fiji, Overseas Indians, Indenture, Diaspora, Family, Marriage, Kinship

\section{INTRODUCTION}

Fiji, in the south west Pacific Ocean is far away from India, yet it has a sizeable population of Indian origin. The history of their immigration and settlement should be seen in the context of British colonialism. Fiji became a part of the British Empire in 1874. The Europeans who settled there became plantation owners. As they found it difficult to secure sufficient local labour, the British government came to their aid and began to import Indian labour through a system of indenture which continued till the end of 1919 (Kumar 2012: 1053).

Indians began to arrive in Fiji by 1879 (Crumpston 1956: 159). They were largely recruited by way of a contract or agreement, often referred to as girmit, especially from north Indian provinces of presentday Uttar Pradesh and Bihar (D'Souza 2001: 1071). The indenture system entailed signing a contract and working on the plantations for five years and another five as free workers after which the labourers became entitled to a paid passage back to India (Ramesh 2017:70). Very few workers signed up for the second contract that allowed them a return passage home. Most remained in Fiji rather than work in the plantation for five more years (Gillion, 1962).In Fiji, the working and living conditions on the plantations was pathetic which gave rise to high death rate including suicide (D'Souza 2001: 1073). Due to a campaign against the indenture system and the pressure of the nationalist movement in India, this system came to an end in 1920 (Kumar 2012: 1053). However, many Indians chose to stay back and became small and marginal farmers and made Fiji their new home (Kumar 2012: 1063)

The aim of this paper is to portray the aspects of marriage, family and kinship among the Indian settlers in Fiji. The first section focusses on aspects of marriage, the wedding ceremony and its significance. The second section focusses on aspects of family which includes household composition, deference and authority patterns, the issues of inheritance and conflict, and the position of women within the family. The third section focusses onkinship ties, including a variety of interpersonal and household relationships. The paper is with reference to the early years of immigration. It thus presents a historical account from a sociological viewpoint. 


\section{Marriage: Selection Of Spouse, Wedding Ceremony And Its Significance}

Marriage is an important stage in a person's life and one which is always ritually observed. It has a considerable structural significance since social ties are not only created through marriage but also reaffirmed (Kapadia: 1955).

\subsection{Selection of Spouse}

Within the Fijian Indian society, matrimonial alliances were usually established between those who belonged to the same caste (Dumont 1971, Ghurye 1969). Caste endogamy was not an overriding consideration, but existed only as an idea. Suitors of another caste of roughly the same status were considered eligible. Within the same caste, marriages were prohibited with anyone with whom a cognate or affinal kinship could be traced. However, this prohibition was limited to close kin, as distant kin soften married. Parents played an important role in the selection of prospective spouses. Marriages by personal choice were rare even in the towns mainly because of the restrictions imposed on the mixing of sexes. People generally sought to have affinal kin in a settlement at a distance. This would breed formality and limit the possibility of quarrels breaking out between the two kin groups (Mayer 1961: 63-64).

\subsection{Wedding Ceremony}

The orthodox wedding of the Hindus was a complex of rituals and ceremonies spread over a number of days both before and after the actual wedding rites took place. Preparations for the wedding started two days before the ceremony took place. Both the bride and the groom were rubbed down with a purificatory paste by the young girls of their respective kin groups. The men of the bride's family helped in the construction of the altar, building a shelter around it, cooking meals and decoration of the marriage booth. These men belonged to the kin group, though some close friends also helped.

On the day of the wedding, as soon as the groom's party arrived, the groom was received as an honoured guest. His feet were washed and tilak applied on his forehead. The bride in the meantime had a bath with the water in which the groom had washed his hair. She then decked herself in a sari and a set of ornaments brought by the groom (Mayer 1961:71).

The actual ceremony usually started late in the night. It first centered around the transfer of the bride from her parents to the care of the groom. This was followed by presentation of gifts by the womenfolk and friends of the bride's side to the groom. The most important rites started after this and the couple circled the altar seven times. Before each round they poured parched rice into a container held by the bride's younger brother. Then the priest asked seven questions of the couple. Next the couple changed places on the bench, the bride now sat on the husband's left side symbolically the weaker side. A further rite followed, where the groom placed sin door in the bride's hair parting.

Next the civil marriage was held. The priest completed the certificate of marriage and the bride and the groom signed it with two witnesses. Mayer reports that it was not until 1928 that an ordinance linked the civil and religious marriages in Fiji, thereby in effect rendering recognition to religious unions (1961:72).After the civil marriage, the couple entered the house of the bride. The ladies of the house played tricks on the groom and the joking relationship between him and his sisters-in-law thus started. The next day, the groom would refuse to eat until the money collected from the guests was presented to him. This comprised the bride's dowry. After the meal the couple left the bride's house.

By and large, religious endogamy was exercised (Schwartz 1967:221). The conjugal relation in Fiji was a stable one. Jayawardena (1983:149) reports that the ideal subordination of the wife was approximated without tension. Divorce or separation was rare. Mayer (1961:165) also maintains that though divorce cases existed, its frequency was too low to be significant.

\subsection{Significance of the Marriage Ceremony}

These weddings had certain significant features. One was that apart from the immediate family members, other kin were not required to participate in the wedding rituals. Secondly as Mayer (1961:77) puts it, "the roles within the rites were not exclusive to certain kin." Thirdly, these weddings emphasized the subordinate position of the bride. The bathing of the bride with the water used by the groom, her placement on the left side of her husband after they circled the sacred fire were an example of this. Further, the bride's side was considered inferior and among the groom's entourage, an atmosphere of superiority existed. Next, the entire wedding ceremony was marked with 
the presentation of gifts. However, no gift came from people of other cultural groups. Mayer (1961:71) is of the view that the pattern of gift-making illustrated the obligation of kinsfolk at weddings and also social obligations of common neighbourhood and cultural groups. Lastly, regarding the role of kin in the secular aspects of the wedding, the whole scale of the wedding depended upon the availability of labour that was largely drawn from the household and the extended family and also from friends. Nobody was hired for this help and so the scale of the wedding was an index of the amount of help a man could garner. Weddings were seen as the concern of the entire settlement so generally people provided services even though one may lack social contacts. Weddings in Fiji Indian settlements were occasions when the settlement itself was represented as one by its members against the other party.

\section{Family: Authority, Inheritance, Conflict And The Position Of Women}

Chandra Jayawardena's article (1983) on the family in Fiji Indian rural society suggests that among the cane farmers, families passed through an extended period until the father passed away. The norm of extended families was achieved frequently as a large number of the residents of each village were members of extended or collateral families (household composed of two brothers). However, this was true only of those Indians who were cane farmers as non-cane farmers mostly resided in nuclear families.

\subsection{Deference and Authority}

Jayawardena (1983:149-50) reports that the Indian families in Fiji were characterized by the domination of men over their wife and children. The wife was subservient and rarely initiated divorce proceedings against her husband. The household head was the sole owner of his property and his wealth. Social esteem and networks determined the son's prospects in the society. The father arranged his son's marriage and expected him to help in the subsequent weddings in the family. A son communicated with his father in formal terms and direct association between them occurred only when the former started working on the farm.

Mayer (1954:4) is of the view that the head of the household was respected and obeyed though family quarrels often weakened his position. The mother played a major part in the management and cohesion of the joint family through her authority over the daughters-in-law. Respect was shown towards the ascending generation and the youngsters deferred to the opinions of the elders. However, in practice, the principle of age commanding respect was dependent upon the immigrant origin of the household heads. Mayer (1954:12) makes a distinction between fathers born in India and those born in Fiji, and suggests that the former would sometimes be unsuccessful in asserting his authority. This occurred due to the difference in values that existed between those born in India and the Fiji-born. The elderly men often fell out with their spendthrift Fiji-born offsprings, thus creating grounds for division.

\subsection{Inheritance}

The inheritance rules were in accordance with the laws of Fiji. In the normal circumstances, rights in equity could be claimed by those defined as family dependents. If a man died before making a will, intestacy expressed the official laws of inheritance in accordance with the categories of "next of kin," each of whom inherited to the exclusion of the other. The wife could be awarded half of the property if there were no children, and one-third if there were any. In reality, if the children were young, the wife became the sole inheritor of the property. She was therefore assigned as the executer of the estate. The enhancing of the legal importance of the wife vis-a-vis other family members resulted in the decline of the importance of patrilineal ties (Jayawardena 1983:167).

Legally, all children had equal rights of inheritance. But in reality, only those family members who lived within the household could claim a share of the inheritance. Married daughters who had received dowries and sons who were provided by farms during their father's lifetime did not make claims. According to the policy of the farm companies, the farm lease could be passed on to a single member who would be treated as the tenant and to whom the company would award a contract (Jayawardena 1983:167).

Indians in Fiji devised other methods so that the farm income was equitably distributed. One custom was for farmers to provide their male heirs with the lease of a farm as collateral. Occasionally 
attempts were made by farmers to divide the farm between his sons so that indivisible ownership could be obtained during his lifetime (Jayawardena 1983: 172).

\subsection{Intra-Familial Conflict}

Conflict within the family arose in a number of relationships. One of the categories was the situation that arose as a result of the altercation between the daughter-in-law and the mother-in-law. This often caused the former to persuade her husband either to gain control over the farm or find a job somewhere else. Conflicts were also common when a son disagreed with his father over various issues related to the management of the farm, the disposal of its income, the household, and his own family requirements (Jayawardena: 1983: 153). Tensions often escalated whenever there was a conflict between an India-born father and Fiji-born son.

Conflict between brothers was also not uncommon. But it was usually the incompatibilities between their wives which were transmuted as disputes between them. Disagreements among them also arose when one of them was made the inheritor of a farm which had been built up through the labour of all.

\subsection{Position of Women}

The Indian women of Fiji played a very traditional and circumscribed role within the household as they were not even allowed to work as agricultural labourers in the family farm. After marriage, women stayed at home and looked after the household, perform religious rituals while men worked outside (Willard: 2018: 230). Their primary interaction was limited to other women of the neighbourhood while men often went out and drank Kava, as its consumption dominated men's social lives in rural Fiji (Tomilson 2007: 1066).

The scarcity of women during the indenture system enhanced their value which led to keen competition among the men for the relatively few available. This competition led to a greater control of females by males especially with regard to their marriage. As a result, the domination of women by men was common.

Within the precincts of the Fiji Indian family the wife played a subordinate role to her husband. Commenting on her status Jayawardena (1983:150) writes that, "although most husbands allowed their wives virtual autonomy in running the household and bringing up the children, it is recognized as delegated authority." However, her relationship with her husband and her in-laws changed after her children were born. Her position in the family was important because she linked it to her parental family, providing her husband with a set of useful ties.

\subsection{Kinship: Interpersonal and Household Relations}

The kinship group forms the core of the Indian cultural integration. The institutions of marriage and family should also be seen in the light of kinship as they create and uphold kinship and in turn are governed by it. In order to understand the interpersonal relations between Fiji Indian kin it is necessary to enumerate the main types of behaviour standardized between kinfolk within the household, kinship relations between household and how kin ties regulated behaviour within a territorial settlement (Mayer 1954:1).

Different types of behavior existed between kinsfolk. There was the relationship of avoidance and joking; and relationship of respect with a fair degree of distance and that of respect equality. Relationships were more formal when they were cross-sexual and were freer between persons of the same sex as sexual differentiation was widespread in the Indian society of Fiji.

\subsection{Avoidance and Joking Relationships}

The relationship of avoidance was usually observed between the wife and the husband's elder brother in whose presence she usually covered her face. Mayer (1961:166) cites an example of a bus driver who collected the fare from his passengers. His sister-in-law when travelling, would give her fare to someone else to pay, or with averted head would leave the fare on the running board for him to pick up later.

Another relationship which approached that of avoidance was that between the parents of the married couple. Their behaviour towards each other was either marked by cordiality or hostility depending upon the relationship between the married couple. It was taken for granted that a man could promote the division of a joint family by influencing his son-in-law. This was one of the reasons why people 
liked their in-laws to live at a distance. Mayer (1954: 4) insists that there was no institutionalized avoidance in this relationship. This relationship of avoidance can therefore be interpreted in terms of "fictional" norms which the Indian immigrants developed in a new social setting.

In contrast to the relationship of avoidance, there existed a joking relationship between a woman and her husband's younger brother. Jokes were allowed between the two and a certain amount of physical contact was also permitted.

Mayer (1961: 167) is of the opinion that these two relationships of avoidance and joking tended to support the authority pattern within the joint family. The avoidance relationship between the wife and the husband's elder brother established that the latter never found himself in a compromising position vis-a vis his younger brother. A freer relationship between the two could possibly subject the elder brother to accusations from the younger brother thus undermining the former's authority. The freedom of men with their elder brother's wife was allowed as the younger brother could be reprimanded by the elder if he became too familiar with his wife. Joking relationship also existed between a man and his wife's brother and sister and also his sister's husband. These people could joke with familiarity insulting each other in a friendly way.

\section{RESPECT AND RESPECTFUl EQUALITY}

Respect was shown towards the ascending generation - maternal and paternal uncles and aunts, parents and parents-in-law. The youngsters deferred to the opinions of their elders and refrained from having over familiar conversations with them. The relation was not reciprocal and it also varied. Parents-in-law were treated more formally. The relationship between the mother-in-law and the sonin-law came close to a relationship of avoidance (Mayer 1954: 4). Fathers were also respected and obeyed though family quarrels often weakened his position. As mentioned earlier, the authority of an India-born father or grandfather was lesser than that of the Fiji-born.

This relationship of respectful equality was the friendship between brothers, sisters, or those cousins who were in the classificatory relationship of siblings. The relationship was based on mutual friendship and confidence at the same time making provisions for the younger to obey the elder if the occasion arose. However, Mayer (1954: 5) adds that such ideas of interpersonal relations did not preclude quarrels. A man quarreled with anyone irrespective of the age factor if he considered that he had sufficient justification. Disputes between father and son, between brothers and between cousin existed especially with regard to the division of the family property.

\subsection{Relationship Between Households}

Within the Fijian Indian community most people in each settlement formed a number of extended families comprising several households. These had evolved partly by the division of households, partly by the arrival of kin from other settlements, and partly by intermarriage. People referred to their kin using these words - parivar, rishtedar and natedar. There were no clear definitions of these three terms though usually the first denoted a group of kin, and the second and third referred to specific people with whom there was a relationship (Mayer 1961:172).

In economic activities, it was the neighbours who helped each other. These people did not belong to any single kinship category and ranged from blood relatives to people who were not actual kinsmen. In day-to-day affairs, it was the agnates (sons, brother's sons) who felt obliged to help each other. This notion of agnates helping each other was part of the belief that paternal descent ties was stronger than maternal ones. Though agnates had the strongest obligations to help each other, actually this was not always forthcoming unless personal relations between them were extremely cordial. The kinship feelings between paternal kin were subordinated to exigencies of distance, past histories of quarrels and personalities. There was no council of kin to uphold the ideal of cooperation (Mayer 1961:175).

Kinship relations were not limited to people who were actually related to each other but also extended to men of other castes, religious or cultural groups by what was called fictitious kinship or what Mayer (1954: 6) calls "assumed" kin. These people were recognized as kin through their co-residence and aid in cooperative activities. The assumed ties however did not extend to the entire kin group but only as far as was convenient. Under this category of fictitious kinship one can also include the "shipmate brother". All Indians who had travelled on the same ship during immigration considered 
themselves brothers. Fiji-born inhabitants considered themselves classificatory brothers since their fathers had been shipmates.

Kinship relations in the Indian community of Fiji helped to regulate and standardize behaviour between the inhabitants. At any given moment, most of the people in a settlement were joined by either real or assumed kin ties. There were several advantages that stemmed from these patterns of interpersonal relations between kin, foremost being their ability to minimize quarrels. "Without them," as Mayer (1954:8) puts it, "behaviour would be a matter of individual temperament and momentary change; with them there was a standard of action to be followed more or less closely." Everybody was accorded with a certain set of behaviour which they were expected to adhere to. This averted any chance of misunderstandings. Even fictitious kinship which did not present any overriding obligation, established and strengthened friendship thus making for congeniality.

\section{CONCLUSION}

In the light of the indenture system that propelled the immigration of Indian labourers to Fiji from 1879 to 1919 , this article makes an attempt to explore the extent to which the Fiji Indian community preserved the traditional institutions of marriage, family and kinship and also the degree of change they underwent. As far as marriage was concerned, the rites and customs that formed the paraphernalia of the ceremony were performed faithfully in the Fiji Indian community, revealing a strong desire to maintain a link with their traditional past. Marriages were arranged by parents and most marital unions were established between castes of similar status. Conjugal relations were characterized by stability and the virtual absence of divorce.

The ideal of the patrilineal extended family was found among the cane farmers. The reason for this could be related to the control of productive property by the father who headed the household and exercised his authority over the family. This was more visible in families were the father was Fijiborn. The increased competition among men for the few Indian women available during the early period of immigration in Fiji led to the exercise of greater control over women. Once married, they were confined to a life of domesticity and played a traditional and circumscribed role.

Kinship patterns among the Indian Fiji community revealed the fact that kin ties, whether real or assumed continued to be strong. Kin folk formed the main grouping among the Indians in Fiji.. Kinship relations were extremely significant and helped to regulate and standardize behaviour between people.

Thus, the Indian Fiji community seems to have retained its own cultural identity and internalized their traditional heritage wherein institutions of marriage, family and kinship have been preserved to a large extent.

\section{REFERENCES}

[1] Cumpston, I. M. “A Survey of Indian Immigration to British Tropical Colonies to 1910," Population Studies, Vol. 10, No. 2, 1956, p. 148-165.

[2] D’Souza, Eugene J. "Indian Indentured Labour in Fiji," Proceedings of the Indian History Congress, Vol. 61, Part 2, 2001, pp.1071-1080.

[3] Dumont, Loius. Homo Hierarchicus: The Caste System and Its Implications, Chicago and London, The University of Chicago Press, 1971.

[4] Ghurye G. S. Caste and Race in India. Popular Prakashan, Mumbai. 1969, 5th ed.

[5] Gillion, K. L. Fiji's Indian Migrants: A History to the End of Indenture in 1920, Melbourne: Oxford University Press, 1962.

[6] Jayawardena, Chandra, "Farm, Household and Family in Fiji Indian Rural Society," in George Kurian and R.P. Srivastava (ed.), Overseas Indians, New Delhi: Vikas Publishing House, 1983, pp. 141-179.

[7] Kapadia K. M. Marriage and Family in India. Oxford University Press, Calcutta. 1955.

[8] Kumar, Mukesh. “A Quest for Identity/Equality: Indians in Fiji, 1879-1970," Proceedings of the Indian History Congress, Vol. 73, 2012, pp. 1053-1064.

[9] Mayer, Adrian C. Peasants in the Pacific: A Study of Fiji Indian Rural Society, Berkeley, University of California Press, 1961. 
[10] Mayer, Adrian C. “Interpersonal Relations Between Fiji Indian Kin,” Man in India, Vol. 34, No. 1, 1954, pp. 1-15.

[11] Ramesh, Sanjay. "Indo- Fiji Counter Hegemony in Fiji: A Historical Structural Approach," Pacific Dynamics: Journal of Interdisciplinary Research, Vol.1, No. 1, 2017, p. 70.

[12] Schwartz, Barton (ed.).Caste in Overseas Indian Communities, California: Chandler Publishing Company, 1967.

[13] Tomilson, Matt. "Everything and its Opposite: Kava Drinking in Fiji," Anthropological Quarterly, Vol. 80, No. 4. 2007, pp. 1065-1081.

[14] Willard, Aiyana K. "Religion and Prosocial Behaviour among the Indo-Fijians," Religion, Brain and Behaviour, Vol. 8, No. 2, 2018, pp. 227-242.

\section{AUTHOR'S BIOGRAPHY}

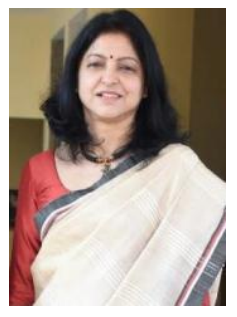

Kiran Jha, was educated at Calcutta University and Jawaharlal Nehru University, New Delhi where she received her doctoral degree. Currently she is an Assistant Professor of Sociology at CSJM University, Kanpur. She has guided over a hundred M.Phil. And postgraduate dissertations. She is the author of Runaway Girls in Britain (Germany: Amani International Publishers, 2009) and several papers in reputed journals including Scottish Affairs. She has earlier worked as a journalist in Goa and as a Research Associate at IIT Kanpur.

Citation: Kiran Jha. "Marriage, Family and Kinship in Fiji among Overseas Indians" International Journal of Humanities Social Sciences and Education (IJHSSE), vol 8, no. 8, 2021, pp. 185-191. doi: https://doi.org/10.20431/2349-0381.0808018.

Copyright: (C) 2021 Authors. This is an open-access article distributed under the terms of the Creative Commons Attribution License, which permits unrestricted use, distribution, and reproduction in any medium, provided the original author and source are credited. 